\title{
All-arthroscopic AMIC procedure for repair of cartilage defects of the knee
}

\author{
Tomasz Piontek $\cdot$ Kinga Ciemniewska-Gorzela $\cdot$ \\ Andrzej Szulc $\cdot$ Jakub Naczk $\cdot$ Michał Słomczykowski
}

Received: 6 May 2011/Accepted: 30 August 2011/Published online: 11 September 2011

(c) The Author(s) 2011. This article is published with open access at Springerlink.com

\begin{abstract}
Purpose Bone marrow mesenchymal stem cells were introduced into clinical practice due to their ability to differentiate into many types of cells. Autologous matrixinduced chondrogenesis (AMIC) combines the microfracture method with matrix-based techniques that utilizes a collagen membrane to serve as a scaffold for new bone marrow mesenchymal stem cells, allowing effective reconstruction of even large fragments of a damaged cartilage surface.

Methods All-arthroscopic technique to repair knee cartilage defects using the AMIC technique, which includes the use of a collagen matrix (porcine collagen type I and III) and fibrin glue-technique presentation.

Conclusion This technical note introduces an all-arthroscopic AMIC technique to reconstruct extensive cartilage
\end{abstract}

T. Piontek · K. Ciemniewska-Gorzela $\cdot$ J. Naczk

Rehasport Clinic, ul. Górecka 30, 60-201 Poznan, Poland

K. Ciemniewska-Gorzela $(\square)$

Department of Pediatric Orthopedic Surgery,

University of Medical Sciences, ul. Podmokła 11/1,

61-424 Poznan, Poland

e-mail: kinga_ciemniewska@ poczta.onet.pl

A. Szulc

Department of Pediatric Orthopedic Surgery,

University of Medical Sciences,

ul. 28 Czerwca 1956r 135/147, Poznan, Poland

M. Słomczykowski

Geistlich Pharma AG, Medical Science,

Bahnhofstrasse 40, 6110 Wolhusen, Switzerland defects (without bone defects). The technique may be used for treatment of all location of knee cartilage lesions.

Level of evidence $\mathrm{V}$.

Keywords Knee $\cdot$ Cartilage $\cdot$ Collagen matrix $\cdot$

All-arthroscopic

\section{Introduction}

Various techniques, both palliative and reparative, have been used to treat cartilage pathology with variable success rates [1-8]. One of the most promising fields of medical scientific research is regenerative medicine. Its major tools include both isolated cells and specially designed biomaterials. Bone marrow mesenchymal stem cells were introduced into clinical practice $[3,5,7]$ due to their ability to differentiate into many types of cells $[1,5,7]$. In fact, bone marrow mesenchymal stem cells are considered to be an attractive source of cells for the regeneration of tissues and organs, including articular surface cartilage $[1,3,5,7]$. The simplest method for utilizing stem cells in the regeneration of a damaged cartilage layer is the microfracture technique [1,9]. Autologous matrix-induced chondrogenesis (AMIC) combines the microfracture method with matrix-based techniques that utilizes a collagen membrane to serve as a scaffold for new cells, allowing effective reconstruction of even large fragments of a damaged cartilage surface [2, 10-13].

The goal of this article is to present an arthroscopic technique for reconstructing damaged knee cartilage fragments using the AMIC technique in conjunction with a collagen matrix (porcine collagen type I and III (Geistlich Pharma AG, Wolhusen, Switzerland)) and fibrin glue (Tissucol, Baxter, Warsaw, Poland). 


\section{Technical note}

The first part of the procedure is diagnostic knee arthroscopy. Standard anterolateral and anteromedial arthroscopic approaches are utilized to evaluate the knee in general, as well as meniscal and cruciate ligament defects. After complete inspection of the joints and assessment of the defects, the chondral lesions are carefully debrided down to the subchondral bone with a curette, spoon, and shaver until a stable shoulder surrounded the defect. Next, the size of each defect was assessed by a circular sharp punch of the appropriate diameter from an OBI Smith and Nephew truffite reconstruction kit (Smith and Nephew, Andover, USA) (Fig. 1). This clearing creates a smooth, flat, circular defect surface with known dimensions and healthy cartilage edges. If the diameter of the cartilage defect does not exceed $11 \mathrm{~mm}$, only one punch is used, and only one reconstruction area was prepared. If the defect is larger, more reconstruction areas are prepared using punches of appropriate sizes. Corresponding numbers of circles are cut (with the same knives) in the Chondro-Gide collagen membrane (Geistlich Pharma AG, Wolhusen, Switzerland) after being moistened with physiological saline (Fig. 2).

The second part of the procedure is performed under dry, arthroscopic conditions. According to recommendations

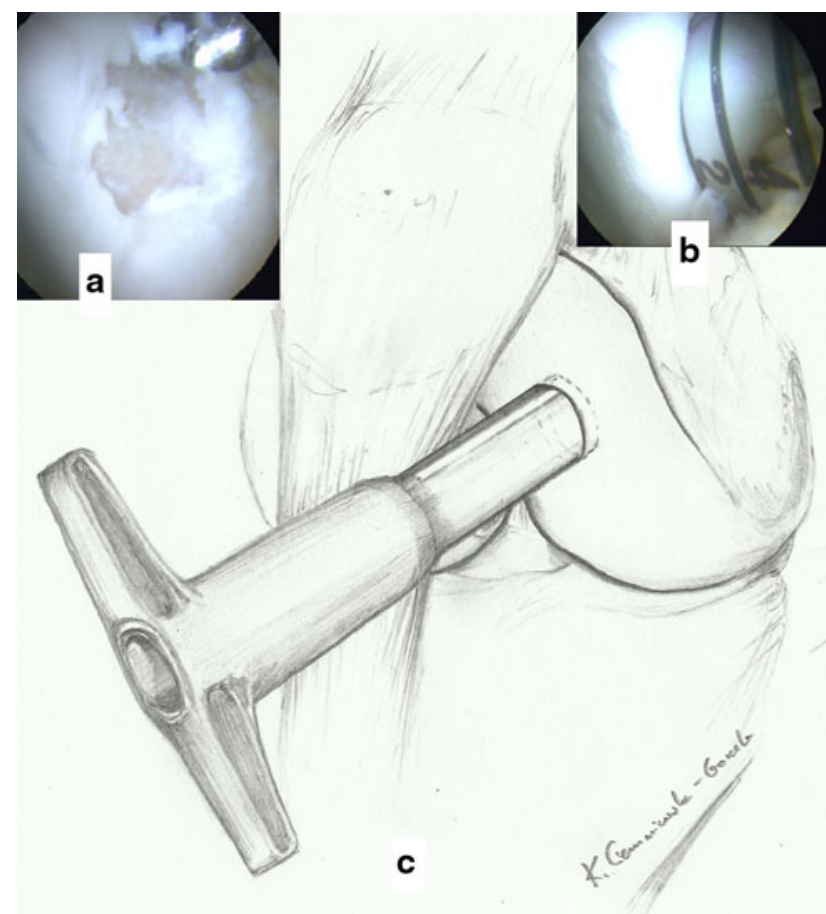

Fig. 1 Knee arthroscopy with fluid irrigation. Joint and cartilage assessment and initial preparation of the cartilage defect area (a). Final preparation of the injured area with a punch from the Smith and Nephew OBI reconstruction kit. An appropriately sized knife was introduced perpendicularly to the damaged surface $(\mathbf{b}, \mathbf{c})$

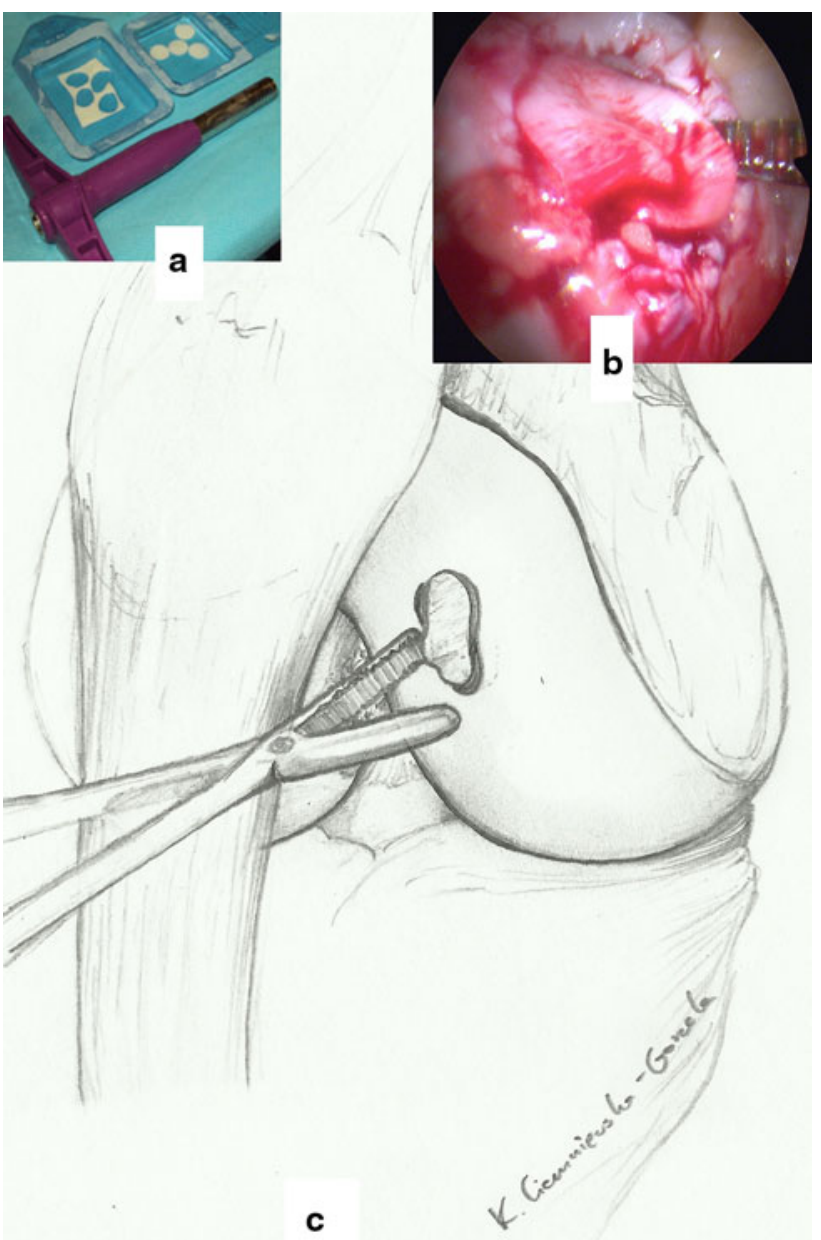

Fig. 2 Preparation of an appropriately sized Chondro-Gide membrane was performed by cutting circles in the moistened rectangular membrane using the knife previously used to prepare the cartilage defect area. Thus, the obtained membrane circles perfectly matched the cartilage defect area in both shape and size (a). Chondro-Gide membrane circles were introduced into the knee using surgical clamps $(\mathbf{b}, \mathbf{c})$

specific to this method, numerous bores are drilled at $5-\mathrm{mm}$ intervals in the subchondral layer with a 1.1-mm K-wire (Fig. 3). Next, Chondro-Gide membrane circles of corresponding diameters are placed in the reconstruction area with Pean clamps. The circular patches overlap. According to the original technique, the porous surface of the membrane is facing the bone surface (Fig. 4). Fibrin glue (Tissucol, Baxter, Warsaw, Poland) is applied to all membrane-covered areas (Fig. 4). Next, excess glue is separated from the surrounding soft tissue, and the glue is left for $5 \mathrm{~min}$ to set. Then, 10 knee movements (consisting of flexion and extension) are performed to check the stability of the reconstructed cartilage surface. If the membranes remained in place, the range of motion of the knee joint in which the reconstructed cartilage surface remained unloaded is recorded so as to determine the safe range of motion for subsequent rehabilitation. 


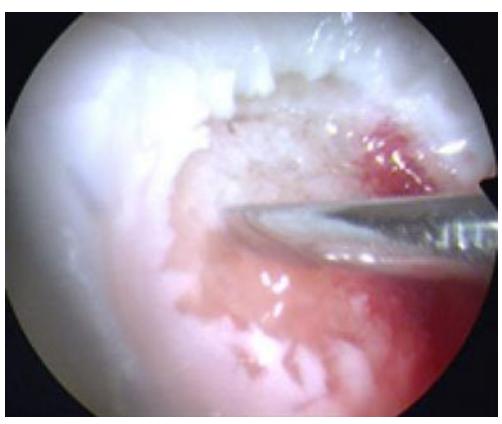

Fig. 3 Evacuation of fluid from the knee. according to the principles of AMIC, bores were drilled in the bone under dry, arthroscopic conditions

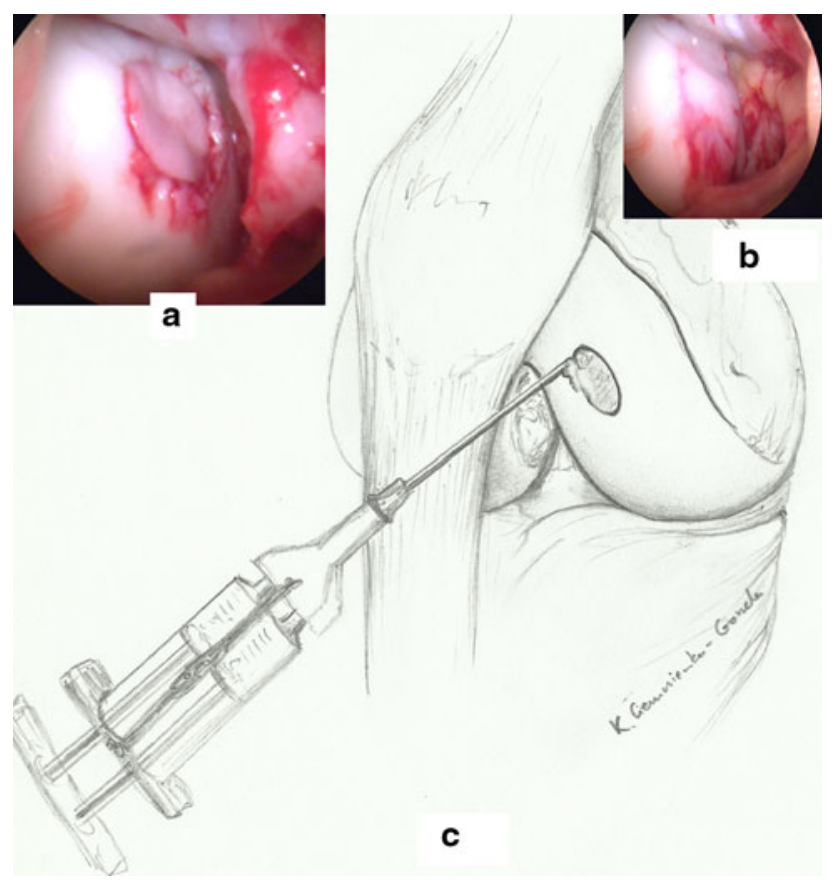

Fig. 4 The view of the Chondro-Gide membrane placed over the defect area. The membrane perfectly matched the prepared cartilage defect area (a). Membranes covered with a tissue glue layer $(\mathbf{b}, \mathbf{c})$

Arthroscopic access wounds are closed. No drains are used. Patients are provided with an adjustable-angle orthosis that stabilized the knee at a $15^{\circ}$ angle for first $24 \mathrm{~h}$ after surgery.

\section{Discussion}

This technical note describes first arthroscopic method to perform the AMIC procedure to treat cartilage defects in the knee. Technical progress has now made it possible to successfully apply arthroscopic techniques to reconstruct the damage of intra-articular knee structures (such as menisci or cruciate ligaments). The evolution of operative technique in knee cartilage repair from open to arthroscopic surgery is known also in autologous chondrocyte implantation [6]. Marciacci et al. described allarthroscopic technique for ACI-Hyalograft C, which is very similar with the technique presented in this paper [6]. The surgical technique for ACI-Hyalograft $\mathrm{C}$ has 2 stages: cartilage biopsy and graft implantation, which is the most important difference with all-arthroscopic AMIC technique. Potential weakness of both all-arthroscopic ACIHyalograft $\mathrm{C}$ and AMIC technique versus open procedures is to use a few overlap circular patches of membrane fixed with glue. It is possible that the patches can move and expose bone. However, mobilization of the implanted patch has not been observed in Marcacci [6] and our series.

In the original AMIC technique (described by Benthien), fibrin glue was used to secure the membrane in the defect area $[2,10,11]$. However, others have reported the use of sutures to prevent membrane relocation. Considering the fact that good results were reported following the use of fibrin glue, the use of sutures appears to be superfluous, when only the cartilage surface needs to be reconstructed [2, 9-11]. Zantop et al. recommend to fix matrix with 1 or 2 biodegradable pins perpendicular to the surface [8]. It is alternative to both gluing and suturing.

Stabilization of the Chondro-Gide membrane with glue requires a dry environment; so to complete the AMIC procedure, the fluid has to be removed before gluing the membrane. Some surgeons make use of special traction sets to generate these surgical spaces and placed patient in prone position [14]. However, we found that with proper supine positioning, most cartilage defects on burdened knee joint surfaces are accessible for dry arthroscopy.

\section{Conclusion}

Here, we present all-arthroscopic technique to reconstruct extensive cartilage defects (without bone defects). The procedure is a single-stage, all- arthroscopic technique based on the open AMIC procedure. Clinical studies comparing this method with other methods or with active rehabilitation in randomized control trials is needed before the method can be recommended as a routine procedure.

Open Access This article is distributed under the terms of the Creative Commons Attribution Noncommercial License which permits any noncommercial use, distribution, and reproduction in any medium, provided the original author(s) and source are credited.

\section{References}

1. Asik M, Ciftci F, Sen C, Erdil M, Atalar A (2008) The microfracture technique for the treatment of full-thickness articular cartilage lesions of the knee: midterm results. Arthroscopy 24:1214-1220 
2. Benthien JP, Behrens P (2010) Autologous matrix-induced chondrogenesis (AMIC) combining microfracturing and a collagen I/III matrix for articular cartilage resurfacing. Cartilage 1:65-68

3. Bentley G, Biant LC, Carrington RW et al (2003) A prospective, randomised comparison of autologous chondrocyte implantation versus mosaicplasty for osteochondral defects in the knee. J Bone Joint Surg Br 85:223-230

4. Gobbi A, Nunag P, Malinowski K (2005) Treatment of full thickness chondral lesions of the knee with microfracture in a group of athletes. Knee Surg Sports Traumatol Arthrosc 13:213-221

5. Hangody L, Kish G, Karpati Z et al (1998) Mosaicplasty for the treatment of articular cartilage defects: application in clinical practice. Orthopedics 21:751-756

6. Marcacci M, Zaffagnini S, Kon E et al (2002) Arthroscopic autologous chondrocyte transplantation: technical note. Knee Surg Sports Traumatol Arthrosc 10:154-159

7. Sgaglione N, Miniaci A, Gillogly S, et al. (2002) Update on advanced surgical techniques in the treatment of traumatic focal articular cartilage lesions in the knee. Arthroscopy (Suppl 1) 18:9-32

8. Zantop T, Petersen W (2009) Arthroscopic implantation of a matrix to cover large chondral defect during microfracture. Arthroscopy 25:1354-1360
9. Gille J, Schuseil E, Wimmer J, Gellissen J, Schulz AP, Behrens P (2010) Mid-term results of autologous matrix-induced chondrogenesis for treatment of focal cartilage defects in the knee. Knee Surg Sports Traumatol Arthrosc 18:1456-1464

10. Benthien JP, Behrens P (2011) The treatment of chondral and osteochondral defects of the knee with autologous matrix-induced chondrogenesis (AMIC): method description and recent developments. Knee Surg Sports Traumatol Arthrosc 19:1316-1319

11. Benthien JP, Behrens P (2010) Autologous matrix-induced chondrogenesis (AMIC). A one-step procedure for retropatellar articular resurfacing. Acta Orthop Belg 76:260-263

12. de Girolamo L, Bertolini G, Cervellin M, Sozzi G, Volpi P (2010) Treatment of chondral defects of the knee with one step matrixassisted technique enhanced by autologous concentrated bone marrow: in vitro characterisation of mesenchymal stem cells from iliac crest and subchondral bone. Injury 41:1172-1177

13. Dhollander AA, De Neve F, Almqvist KF, Verdonk R, Lambrecht S, Elewaut D, Verbruggen G, Verdonk PC (2011) Autologous matrix-induced chondrogenesis combined with platelet-rich plasma gel: technical description and a five pilot patients report. Knee Surg Sports Traumatol Arthrosc 19:536-542

14. Siebold R, Sartory N, Yang Y, Feil S, Paessler HH (2011) Prone position for minimal invasive or all-arthroscopic autologus chondrocyte implantation at the patella. Knee Sur, Sports Traumatol Arthrosc Published online: 09 April 